\title{
DA DECODIFICAÇÃO À LEITURA CRÍTICA: POR ONDE TRANSITA O LIVRO DIDÁTICO DE ESPANHOL?
}

Desde la descodificación hacia la lectura crítica: ¿Por dónde va el libro didáctico de español?

Elzimar Goettenauer de Marins COSTA - UFMG

\section{RESUMO:}

De acordo com o edital do PNLD 2012 - Ensino Médio, o livro didático deve "favorecer a formação de um leitor crítico e interativo, capaz de ultrapassar a mera decodificação de sinais explícitos". Esse princípio nos leva a perguntar quais pressupostos teóricos deveriam fundamentar tanto a elaboração dos livros quanto sua avaliação, visto que as Orientações Curriculares para o Ensino Médio estabelecem diferenças relevantes entre leitura crítica e letramento crítico, as quais, por sua vez, implicam formas diversas de trabalho com o texto. Considerando tais diferenças, os objetivos deste artigo são: apresentar os resultados de uma análise das concepções de leitura subjacentes às atividades com textos nas três coleções didáticas de espanhol aprovadas no PNLD 2012 (El arte de leer español, Enlaces e Síntesis) e discutir se as referidas atividades podem contribuir para o desenvolvimento do letramento crítico dos alunos.

PALAVRAS CHAVE: leitura, letramento crítico, livro didático.

\section{RESUMEN:}

Según la convocatoria del PNLD 2012 - Ensino Médio, el libro didáctico debe "facilitar la formación de un lector crítico e interactivo, capaz de ir más allá de la somera descodificación de señales explícitas". Dicho principio nos lleva a preguntar qué supuestos teóricos deberían fundamentar tanto el diseño de los libros como su evaluación, ya que las Orientações Curriculares para o Ensino Médio establecen diferencias relevantes entre lectura crítica y literacidad crítica, las cuales, a su vez, implican formas distintas de trabajo con el texto. Teniendo en cuenta esas diferencias, los objetivos de este artículo son: presentar los resultados de un análisis de las concepciones de lectura implícitas en las actividades con textos en las tres colecciones didácticas de español aprobadas en el PNLD 2012 (El arte de leer español, Enlaces y Síntesis) y discutir si tales actividades pueden contribuir al desarrollo de la literacidad crítica los estudiantes.

PALABRAS CLAVE: lectura, literacidad crítica, libro didáctico.

\section{INTRODUÇÃO}

Os últimos editais do Programa Nacional do Livro Didático (PNLD) - edições de 2011 para o Ensino Fundamental e de 2012 para o Ensino Médio - incluiu pela primeira vez o componente curricular Língua Estrangeira Moderna (Espanhol e Inglês). As obras inscritas deveriam atender a critérios gerais, relacionados a aspectos legais, e a critérios específicos, próprios de cada disciplina. 
No Anexo III do edital do PNLD 2012, que trata dos "Princípios e critérios para a avaliação de obras didáticas destinadas ao Ensino Médio", afirma-se na seção dedicada às "Linguagens, códigos e suas tecnologias" que o livro didático representa um objeto de cultura e deve suscitar, no trabalho com as linguagens, o interesse do estudante para questões bem mais amplas e relevantes socialmente. E ainda:

Deve favorecer a convivência do aluno com diferentes representações de linguagem, com diferentes modalidades de tipos e gêneros de textos, de épocas, regiões, funções, registros diversificados. Deve favorecer a formação de um leitor crítico e interativo, capaz de ultrapassar a mera decodificação de sinais explícitos. (BRASIL, 2009, p. 22; grifos meus)

Esse princípio sugere uma importante questão: quais pressupostos teóricos deveriam fundamentar a produção dos livros e a sua avaliação? Essa interrogação se justifica pelo fato de que as Orientações Curriculares para o Ensino Médio (OCEM), no capítulo dedicado aos Conhecimentos de Línguas Estrangeiras, estabelecem diferenças significativas entre leitura crítica e letramento crítico, sinalizando as implicações para o trabalho com o texto. Assim, segundo a perspectiva teórica adotada, as atividades de leitura podem dar ênfase à compreensão geral, à localização de informações específicas, ao reconhecimento da função de determinados elementos linguísticos, à identificação da ideia principal e das intenções do autor, aos conhecimentos prévios e à opinião do leitor etc.; ou, por outra parte, podem focalizar os fatores socioculturais que condicionam a produção e a compreensão dos textos, a multiplicidade de linguagens e significados, os valores e as visões de mundo subjacentes aos textos, a origem social e histórica dos conhecimentos prévios do leitor etc.

Tendo em vista o exposto, os objetivos deste artigo são: apresentar os resultados, por ora parciais, de uma pesquisa feita com o intuito de verificar as concepções de leitura subjacentes às atividades de compreensão leitora nas três coleções didáticas de espanhol aprovadas no PNLD 2012 (El arte de leer español, Enlaces e Síntesis) e iniciar uma reflexão sobre a aproximação ou o distanciamento dessas atividades com relação ao letramento crítico dos alunos.

O desenvolvimento do tema considerará três instâncias: a do edital do PNLD 2012, a dos livros didáticos analisados e a das teorias do Letramento Crítico.

\section{O NORTE APONTADO PELO EDITAL}


Retomando o fragmento destacado na citação feita na introdução, podemos iniciar nossas ponderações discutindo o que pode ser entendido como leitor crítico e interativo. Ao se falar de modelos de leitura, normalmente se identificam três concepções principais:

- concepção linguística (bottom up): diz respeito à leitura literal, à decodificação das unidades linguísticas menores (palavras) até as maiores (orações e parágrafos); o foco está no código;

- concepção psicolingüística (top down): se refere à leitura com uso de estratégias, principalmente formulação de hipóteses sobre o conteúdo do texto e inferências acerca do que não está dito explicitamente, mas pode ser identificado nas entrelinhas, a partir dos conhecimentos prévios do leitor; o foco é o leitor e sua capacidade de empregar estratégias cognitivas;

- concepção interativa: pressupõe o uso simultâneo da decodificação e da inferência. No entanto, “o foco passa a ser não mais sobre o que o texto diz em função da interação do leitor com os dados linguísticos, mas sobre o que o autor quis dizer, isto é, suas intenções. Nessa visão, o ato de ler passa a ser visto como um ato comunicativo". (KATO, 1985, p. 114-115)

Desse modo, seria possível interpretar que o leitor interativo, mencionado no edital, seria aquele capaz de identificar o que o autor quis comunicar por meio do texto, interagindo com ele.

E quanto a ser um leitor crítico?

Segundo Cervetti; Pardales; Damico (2001), numa perspectiva derivada da tradição liberalhumanística (décadas de 1950-60), a leitura crítica demanda um conjunto de habilidades que inclui, dentre outras, a investigação das fontes (de que instituição ou esfera de atividades é o texto ${ }^{1}$ ), o reconhecimento do propósito do autor, a distinção entre opinião e fato e a realização de inferências. Ler é uma atividade que pode ajudar o leitor a aprender sobre o mundo e a decifrar se uma informação é válida ou não; o conhecimento é entendido como um processo de análise racional da realidade, referente supremo para a interpretação. Há uma separação entre fatos, inferências e julgamentos do leitor; uma correta interpretação do texto estaria associada à identificação da intenção do autor, que pode estar escondida nas entrelinhas.

Pode-se afirmar que a atitude crítica complementa a leitura interativa: o leitor identifica a intenção do autor e verifica, por meio de procedimentos de análise e tomando como referência o conhecimento da realidade, o teor de verdade do que é dito, comparando seu próprio julgamento com o de outros leitores.

As concepções de leitura orientam as questões formuladas para a compreensão leitora. As perguntas baseadas no modelo linguístico focalizam o que está dito explicitamente, dessa forma

\footnotetext{
${ }^{1}$ Os textos científicos são considerados como verdades porque informam sobre o mundo, já um texto literário não é fonte de informações verdadeiras, deve ser questionado ou simplesmente apreciado.
} 
basta localizar a informação no texto e transcrevê-la. Em alguns casos, nem é necessário ler integralmente o texto para responder, assim como, muitas vezes, não é preciso fazer qualquer modificação para adaptar o fragmento encontrado ao formato de uma resposta. As questões orientadas pelo modelo psicolingüístico estimulam o aluno a predizer o conteúdo do texto e a preencher os vazios de informação usando seus conhecimentos prévios; as perguntas podem solicitar a formulação de hipóteses e a inferência, por exemplo. Quando têm como referência o modelo interativo, as perguntas potencializam o uso das estratégias cognitivas e levam o aluno a ter um papel ativo na leitura, motivando-o a interagir com o autor, por meio do texto; as questões podem solicitar a explicação do que o autor quis dizer e de suas intenções. Já para promover a leitura crítica, as questões podem, como apontam as OCEM (BRASIL, 2006, p. 115), motivar o aluno a observar a forma e a função dos textos, a identificar e criticar as razões do(s) autor(es) do texto, a verificar, por exemplo, dados e argumentos, analisando em que medida conferem credibilidade a uma informação ou fundamentam uma interpretação.

Voltando ao PNLD, embora os editais não tenham a finalidade de apresentar um suporte teórico para os autores e para os avaliadores, o da edição de 2012, além de discorrer sobre algumas características do livro didático, apresenta um quadro de referência com relação às linguagens, que são compreendidas como ${ }^{2}$ :

i) uma atividade funcional, destinada a cumprir um objetivo;

ii) uma atividade de interação, envolvendo dois ou mais interlocutores;

iii) uma atividade social conforme determinações espaço-temporais de cada cena de interlocução;

iv) uma atividade política que envolve valores, concepções e ideologias;

v) uma atividade em estado de permanente construção;

vi) uma atividade historicamente ininterrupta e continuada;

vii) uma atividade eminentemente textual e discursiva;

viii) uma forma de criação de objetos artísticos;

ix) um conjunto complexo de regularidades que se subordinam às necessidades interativas dos sujeitos;

x) uma prática de interação que se manifesta verbalmente em diferentes línguas, possibilitando o conhecimento de diferentes regiões e culturas. (BRASIL, 2009, p. 21-22; grifos meus)

A partir desse quadro de referência, é possível perceber que havia um norte para a produção das obras, visto que o objeto de estudo do livro didático de LE é justamente a linguagem. Com

\footnotetext{
${ }^{2}$ Apresento os pressupostos de forma resumida.
} 
relação ao tema que nos interessa aqui - a leitura - os pressupostos elencados no edital nos servem para apontar aspectos importantes, que ampliariam os horizontes da compreensão leitora. Eles nos permitem depreender que o trabalho com o texto deveria concebê-lo como uma forma de manifestação da linguagem e, portanto, uma atividade de interação, social, política, em estado de permanente construção, considerando os interlocutores envolvidos e as determinações espaçotemporais de cada cena de interlocução. Nessa perspectiva, as perguntas deveriam considerar, dentre outros aspectos, as circunstâncias socioculturais tanto da criação (escrita) quanto da recepção (leitura) dos textos e a dimensão ideológica tanto das possíveis intenções implícitas nos textos quanto da própria compreensão.

Passando aos critérios dispostos no edital, são 16 os específicos para o componente curricular Língua Estrangeira Moderna; interessam-nos aqui os critérios 8 e 9, que tratam da compreensão leitora:

(8) valoriza nas atividades de compreensão leitora o processo que envolve atividades de pré-leitura, leitura e pós-leitura;

(9) propõe estratégias de leitura, tais como localização de informações explícitas e implícitas no texto, levantamento de hipóteses, produção de inferência, compreensão detalhada e global do texto, dentre outras. (ibidem, p. 24)

Embora os critérios específicos não devam se estender em detalhes, pois se desdobrariam em muito mais de 16, acabamos sentindo, à primeira vista, certo descompasso entre o princípio de formar leitores interativos e críticos e o quadro de referências, por um lado, e os critérios propriamente ditos, por outro. Parece que, diante das implicações decorrentes do desenvolvimento da leitura crítica e da abordagem do texto como atividade de linguagem (social, política, em permanente construção), os requisitos demandam pouco do trabalho de compreensão leitora.

\section{O QUE DIZEM E FAZEM OS LIVROS DIDÁTICOS}

As três coleções de espanhol aprovada no PNLD 2012 são as seguintes: El arte de leer español (PICANÇO; VILLALBA, 2010), Enlaces (OSMAN et al, 2010) e Síntesis (MARTIN, 2010). Considero na minha análise apenas as seções dos livros que são identificadas pelos próprios autores como dedicadas à compreensão leitora, embora apareçam textos acompanhados de perguntas em outras partes. Na fase apresentada neste artigo, levei em conta somente o trabalho de leitura realizado nas unidades, deixando para a segunda fase as atividades complementares do Repaso, em Enlaces, e dos Apartados 1 e 2, em Síntesis. 
Primeiramente, mostrarei como são explicadas em cada coleção as seções dirigidas à leitura, ressaltando alguns pontos que merecem atenção; em seguida, comentarei os tipos de exercícios propostos nas três obras, tomando como referência o edital, e, por fim, farei algumas considerações sobre a leitura na perspectiva do letramento crítico.

Devido ao fato de que El arte de leer español é, assumidamente, uma obra centrada na leitura (cf. p. 10 do Manual do Professor), deixarei os comentários sobre ela por último. E, como há mais atividades de compreensão leitora nessa coleção, haverá também mais aspectos a destacar.

Antes de passar aos comentários resultantes da análise, gostaria de esclarecer o sentido dado às palavras tema e texto: quando uso a palavra tema, me refiro ao tema da unidade, focalizado e aprofundado por meio dos textos, sendo assim, ao dizer que uma pergunta se refere ao tema, quero realçar que a resposta não depende necessariamente da leitura do texto; por outro lado, quando uso a palavra texto, estou falando do texto propriamente dito, objeto da leitura.

Quanto à análise das atividades de leitura, pré-leitura e pós-leitura, mencionadas no critério 8 , usarei como referência os Parâmetros Curriculares Nacionais para o Ensino Fundamental $-3^{\circ}$ e $4^{\circ}$ ciclos, Língua Estrangeira (BRASIL, 1998, p. 91-93)

- pré-leitura: sensibilização do aluno quanto aos possíveis significados a serem construídos na leitura. Engloba a ativação do conhecimento prévio com relação aos conhecimentos de mundo e à organização textual: explorar título, subtítulo, figuras, gráficos, desenhos, autor, fonte, itens lexicais, constituintes e distribuição gráfica do texto; identificar o autor, o leitor virtual, quando e onde o texto foi publicado e com que propósito;

- leitura: fase de projeção dos conhecimentos prévios nos elementos sistêmicos do texto; o aluno deve ser orientado a adivinhar o significado das palavras desconhecidas por meio das pistas contextuais e, igualmente, a entender que não é necessário conhecer todas as palavras para poder ler. É importante propiciar o reconhecimento das informações centrais e dos detalhes;

- pós-leitura: fase destinada a levar o aluno

a pensar sobre o texto, emitir suas reações e avaliar, criticamente, as idéias do autor. O foco essencial é no relacionamento do mundo do aluno com as idéias do autor. Esses aspectos mais críticos evidenciados nesta fase devem perpassar toda a atividade de leitura, embora pedagogicamente estejam concentrados aqui. (ibidem, p. 92)

\section{Enlaces}

Características gerais da coleção:

\footnotetext{
${ }^{3}$ Nem os Parâmetros Curriculares para o Ensino Médio, publicados em 1999, nem as OCEM (2006) mencionam a pré-leitura e a pósleitura.
} 
- cada volume tem 8 unidades com uma média de 18 páginas cada uma;

- seções: Hablemos de...; ;Y no sólo esto!; Manos a la obra; En otras palabras...; Como te decía...;

Más cosas; Así me veo;

- inclui um "Repaso"4 a cada duas unidades (4 por volume).

A seção dedicada à compreensão leitora é ;Y no sólo esto!, explicada assim:

\begin{abstract}
Pretende orientar y desarrollar estrategias de lectura en lengua española a partir del trabajo con los más diversos géneros discursivos. Se proponen actividades diversificadas de comprensión lectora, ampliando la perspectiva reflexiva del tema tratado, de la gramática y del vocabulario. (OSMAN et al., 2010, p. 4; grifos meus)
\end{abstract}

Ao considerar as estratégias de leitura, a coleção está em sintonia com o critério 9 ("propõe estratégias de leitura, tais como localização de informações explícitas e implícitas no texto, levantamento de hipóteses, produção de inferência, compreensão detalhada e global do texto, dentre outras”) do edital. Com relação às atividades diversificadas de compreensão leitora, deve-se notar que englobam a reflexão sobre o tema tratado, a gramática e o vocabulário, mas não se inclui o propósito de refletir sobre o próprio texto. Embora não se possa com base apenas na explicação entender se a reflexão abarcará também o modo como o tema é abordado e discutido, esse pode ser o indício de um trabalho de leitura que não privilegia o texto.

A obra dedica 3 páginas em cada unidade para a compreensão leitora. Na primeira página, realiza-se a pré-leitura: uma preparação para ler o texto que, na maior parte dos casos, introduz o tema e enfoca o vocabulário, destacando palavras supostamente desconhecidas pelo aluno. São exercícios variados: completar lacunas, responder, marcar a resposta certa, associar colunas, conversar com o colega. A estratégia de formulação de hipóteses com base nos conhecimentos prévios, levando em conta título, autor, fonte, leitor virtual etc. praticamente não é explorada. Na segunda página, apresenta-se o texto e na terceira estão os exercícios de leitura; as perguntas requerem do aluno: localização de informações explícitas, ativação do conhecimento prévio para ampliar alguma informação ou ideia presentes no texto, expressão da opinião pessoal sobre o tema, estudo do vocabulário e de conteúdos gramaticais, localização de informação implícita e inferência. Dessas, a mais frequente é a primeira e a menos frequente, a última. Não é feito trabalho de pósleitura; alguns exercícios que poderiam propiciar uma avaliação crítica das ideias contidas no texto não são aproveitados com esse fim. Por exemplo:

4. Lee uno de los fragmentos de la conferencia de Hebe Bonafini y de la canción Desapariciones del panameño Rubén Blades. ¿Qué revelan sobre la actitud de la mayor parte de la gente hacia los desaparecidos? Respuesta esperada: indiferencia, desprecio, miedo hacia a los que se oponían al gobierno. (OSMAN et. al, 2010, v. 2, p. 31)

\footnotetext{
${ }^{4}$ As atividades com textos realizadas no Repaso não foram consideradas nesta primeira fase da análise.
} 
Nota-se que o aluno deve apenas mencionar as atitudes das pessoas com relação aos desaparecidos, não é necessário questionar essas atitudes, comentá-las ou opinar sobre elas.

\section{Síntesis}

Características gerais da coleção:

- cada volume tem 8 unidades com uma média de 18 páginas cada uma;

- seções: Para oír y comprender, Algo de vocabulario, Gramática Básica, Para leer y reaccionar (Texto principal), Aprende un poco más, Para charlar y escribir, Para leer y reflexionar (Texto complementario), ¡Evalúate!;

- inclui um Apartado 1 (depois da unidade 4) e um Apartado 2 (depois da unidade 8) ${ }^{5}$.

As seções dedicadas à compreensão leitora são Para leer y reaccionar e Para leer y reflexionar, assim definidas, respectivamente, na coleção:

\footnotetext{
Essa seção traz textos de gêneros discursivos variados [...] para que sejam trabalhadas a leitura e a compreensão textual. No entanto, como se sabe, o trabalho com textos frequentemente extrapola o objetivo inicial e desencadeia outras aprendizagens.

Os textos literários, além de favorecer o contato com múltiplas manifestações culturais, não raro propiciam reflexões que contribuem para a formação do indivíduo e para a humanização das relações interpessoais.

Cabe lembrar que a leitura de qualquer tipo de texto pode favorecer, dependendo da relevância do tema e da abordagem, o amadurecimento de reflexões sobre os problemas que nos afetam coletivamente. Após a leitura, o aluno deverá responder a algumas questões que têm a função de verificar a compreensão e que convidam a opinar sobre elementos específicos do texto ou sobre o seu sentido global. (MARTIN, 2010, Manual do Professor, p. 5; grifos meus)
}

Essa seção traz textos atuais e, muitas vezes, polêmicos, que visam à ampliação do tema tratado no capítulo. Nas atividades do item IV deste manual há sugestões de trabalho com esses textos que podem servir de ponto de partida para uma aula de leitura e conversação. (ibidem, p. 6; grifos meus)

É importante chamar a atenção, em primeiro lugar, para a separação feita entre leitura e compreensão textual, como se fossem dois momentos ou duas etapas diferentes. Talvez o pressuposto subjacente a essa distinção seja o entendimento da leitura como decodificação (reconhecimento de cada palavra do texto) e da compreensão como apreensão do significado do que está escrito. Contudo, como nos adverte Marcuschi, "ler e compreender são equivalentes [...]. Ler equivale a ler compreensivamente" (2008, p. 239). Em segundo lugar, é possível deduzir que a leitura e a compreensão constituem o objetivo inicial, que pode ser extrapolado se o texto desencadear outras aprendizagens. Uma vez mais se nota a distinção entre duas possíveis etapas: a da compreensão e a das outras aprendizagens. Outra questão a levantar diz respeito ao amadurecimento de reflexões subordinado à relevância do tema e à abordagem. Não fica claro se essa abordagem se refere ao tratamento do tema no texto ou à discussão sobre o tema promovida pelas atividades de

\footnotetext{
${ }^{5}$ As atividades com textos da seção ¡Evalúate! e dos Apartados não foram analisadas nesta primeira fase.
} 
leitura. Considerando-se que são dois caminhos diferentes, implicando consequentemente reflexões de distintas naturezas, a questão é relevante. Por fim, vale a pena observar que o enfoque do tema da unidade (e não do texto como objeto da compreensão) é reiterado na segunda seção.

A obra dedica 2 páginas à leitura na seção Para leer y reaccionar. Na primeira página, apresenta-se o texto e na segunda, estão as atividades de leitura. Os exercícios requerem do aluno: localização de informações explícitas, expressão da opinião pessoal sobre o tema, ativação do conhecimento prévio para ampliar alguma informação ou ideia presentes no texto, estudo do vocabulário e de conteúdos gramaticais e tradução. Não há atividades de pré-leitura e pós-leitura. Na seção Para leer y reflexionar apresenta-se somente o texto, não há exercícios no livro do aluno para explorá-lo. No Manual do Professor há sugestões de atividades variadas para serem desenvolvidas a partir do texto. Pode-se dizer que o texto funciona como pretexto para focalizar algum aspecto gramatical ou lexical, ou para promover debates, trabalhos em grupo, conversação e avaliação, sempre tomando o tema como eixo.

\section{El arte de leer español}

Características gerais da coleção:

- cada volume tem 4 unidades; o número de páginas por unidade varia de 21 a 40;

- seções: ¡Mira!, ¡Acércate!, ¡Ojo!, Ahora tú, ¡Dale!, Para consultar, Para curiosear, Para escuchar;

- as seções ¡Mira!, ¡Acércate! e ¡Dale! se repetem várias vezes, de acordo com o número de textos, e são explicadas do seguinte modo:

\footnotetext{
¡Mira! - Las actividades [...] fueron pensadas en función de las características generales de la composición textual: las figuras o fotos ilustractivas, las formas más o menos convencionales de iniciar o terminar el texto, de distribuir las informaciones, el vehículo en que el texto fue publicado, y así sucesivamente. [...]Las informaciones sacadas en ese momento pueden ayudar al alumno a elaborar hipótesis sobre los textos, que podrán o no ser comprobadas [...]. (PICANÇO; VILLALBA, 2010, Manual do Professor, p. 18)

¡Acércate! - Las actividades [...] fueron pensadas en función del reconocimiento y comprensión del contenido del texto, de los recursos expresivos usados por su autor, sus intenciones, sus ideas más o menos explícitas en la superficie del texto, las características generales de la comprensión textual: vocabulario contextualizado, marcadores de la organización textual, conectores, las formas más o menos convencionales de iniciar o terminar el texto, de distribuir las informaciones principales y complementarias, etc. [...] Esta actividad es la principal en el desarrollo de las prácticas de lectura, pues obliga a los alumnos a reflexionar sobre el texto, no solo sobre su organización interna, sino también sobre los aspectos sociohistóricos que condicionan su composición. (ibidem, p. 19)

¡Dale! - Las actividades [...] fueron pensadas para que los alumnos puedan ir adelante, o sea, estableciendo la confrontación entre sus conocimientos previos y las informaciones presentadas en los textos. Así, podrán reflexionar sobre los procesos de interacción establecidos entre el autor del texto, su vehículo de publicación y el lector. [...] Aquí se establecen comparaciones entre los textos, relaciones entre ellos y las obras de arte presentadas en la colección. También se proponen investigaciones complementarias, otras lecturas, etc. (ibidem, p. 20)
} 
Embora no Manual do Professor da referida coleção não se faça nenhuma menção sobre a correspondência entre essas seções e as fases do trabalho de compreensão leitora nomeadas no critério 8, as explicações dadas nos permitem constatar que as atividades da obra objetivam levar o aluno, primeiramente, a observar a composição textual (pré-leitura), em seguida, a reconhecer e compreender o conteúdo do texto (leitura) e, finalmente, a refletir a partir do confronto entre seus conhecimentos anteriores e as informações apresentadas no texto (pós-leitura). Também percebemos a preocupação em atender os critérios, na referência às estratégias - formulação de hipóteses, identificação de ideias explícitas e implícitas e reconhecimento da intenção do autor (que se dá por meio de inferências). Destacam-se os seguintes pontos: a alusão a elementos gráficos, tais como figuras e fotos, como fatores que podem contribuir para a formulação de hipóteses sobre o texto; o intento de estimular o aluno a refletir tanto sobre a organização interna do texto quanto sobre os aspectos sócio-históricos que condicionaram sua produção, e também sobre a interação autor veículo de publicação - leitor; o propósito de estabelecer relações dos textos entre si e com as obras de arte apresentadas na coleção. Entretanto, podemos questionar: não seriam relevantes também os aspectos sócio-históricos da leitura?

O foco desta coleção, como já foi dito, é a leitura. Cada unidade apresenta vários textos; a unidade 1 (Identidad) do volume 1, por exemplo, contém 18 textos, incluindo-se os não verbais. Normalmente, são de gêneros variados; na unidade mencionada há, dentre outros: poema, biografia, entrevista, mapa, reprodução de quadros, tira cômica etc. A maior parte dos textos tem atividades das três seções, excetuam-se apenas os que seriam complementares: Para curiosear e Para consultar. O trabalho de pré-leitura é mais diversificado no volume 1, especialmente na primeira unidade, todavia, não explora de fato, em nenhum dos 3 volumes, elementos da composição textual como subtítulos, número de parágrafos, autoria, suporte original etc., atendo-se mais à formulação de hipóteses a partir do título do texto.

Os exercícios de leitura requerem do aluno: observar as imagens, ativar os conhecimentos prévios, localizar informações explícitas, reconhecer informações implícitas, fazer inferências, relacionar os textos a partir da discussão do tema, manifestar opinião pessoal e pensar criticamente sobre o tema, relacionar o tema à sua realidade. A diversidade de exercícios é mais explorada e mais equilibrada no volume 1 . Nos volumes 2 e 3, estimula-se o uso do dicionário para verificar significados de palavras e expressões que aparecem nos textos, é dada mais ênfase à localização de informações explícitas, há menos perguntas acerca da relação entre os textos, mais questões de múltipla escolha e mais exercícios com foco em aspectos gramaticais, reescrita de frases substituindo 
palavras e expressões por sinônimos ou vinculando as afirmações corretas sobre o conteúdo do texto e cópia das afirmações verdadeiras.

As questões de pós-leitura, na maior parte dos casos, motivam a pesquisa para aprofundamento e ampliação do tema tratado nos textos, estimulando a interdisciplinaridade e o confronto com a realidade do aluno, mas não chega a propor que o aluno se posicione criticamente a respeito das ideias do autor.

Retomando as explicações dadas sobre o trabalho pretensamente realizado nas três seções voltadas para a compreensão leitora, deve-se destacar que não se promove efetivamente na coleção uma reflexão sobre a organização interna dos textos. Apesar de serem apresentados, em algumas unidades, textos com os parágrafos desordenados para que o aluno os numere na ordem correta, não há nenhuma questão que peça, por exemplo, a justificativa para a sequência escolhida ou estimule o aluno a explicar por que é possível perceber que o texto não faz sentido ou fica confuso da forma como está organizado. Os aspectos sócio-históricos relacionados à composição de alguns textos são mencionados como forma de contextualização, mas não são abordados como aspectos que condicionam a produção textual. Também não se encontra na obra nenhum exercício que realmente suscite discussão com foco nos "procesos de interacción establecidos entre el autor del texto, su vehículo de publicación y el lector".

\section{A COMPREENSÃO LEITORA NAS TRÊS COLEÇÕES}

As coleções procuram cumprir, em diferentes graus, os critério 8 e 9 do edital:

\footnotetext{
(8) valoriza nas atividades de compreensão leitora o processo que envolve atividades de pré-leitura, leitura e pós-leitura;

(9) propõe estratégias de leitura, tais como localização de informações explícitas e implícitas no texto, levantamento de hipóteses, produção de inferência, compreensão detalhada e global do texto, dentre outras. (BRASIL, 2009, p. 24)
}

Somente El arte de leer español propõe sistematicamente atividades de pré-leitura, leitura e pós-leitura; Enlaces tem atividades de pré-leitura e leitura e Síntesis, somente de leitura. Nota-se que a pré-leitura, quando realizada, não se constitui num trabalho voltado concretamente para aqueles aspectos da composição textual que podem ser detectados por meio de um olhar panorâmico dirigido ao texto: gênero, número de parágrafos, presença ou não de subtítulos, gráficos e ilustrações, lugar e data de publicação, nome do autor, algum tipo de destaque como negritos, sublinhados, aspas, tópicos etc. No caso de gêneros como charges, tiras cômicas, folhetos e propagandas, os elementos não-verbais não são explorados como elementos que podem encaminhar ou influenciar a 
compreensão. Geralmente, a atividade que antecede a leitura se restringe a introduzir o assunto tratado no texto, o qual, por sua vez, é o fio condutor da unidade.

As atividades de leitura nas três coleções são diversificadas com relação à tipologia: perguntas de respostas abertas, de respostas fechadas, de múltipa escolha, exercícios de completar lacunas, associar colunas, marcar V (verdadeiro) ou F (falso), fazer tradução, reescrever frases etc. Também são diversificadas com relação ao que o aluno deve fazer com o texto: procurar uma informação e transcrevê-la, usar seus conhecimentos prévios para explicar algum dado ou argumento apresentado, opinar sobre o tema, reconhecer informações implícitas, citar algo da sua realidade que se relacione com o assunto abordado, identificar a ideia principal, inferir a intenção do autor etc. Contudo, além do predomínio, nas três obras, de perguntas de localização de informação explícita, o uso das estratégias não é potencializado; não se explora, por exemplo, dentre outras possibilidades, a relação entre formulação de hipóteses ou inferência e gêneros textuais. Com relação à leitura crítica, pode-se dizer que ela é feita superficialmente, por meio das perguntas nas quais o aluno é convidado a emitir sua opinião sobre o tema - mas nunca sobre o texto -, a evocar conhecimentos prévios para detalhar ou confirmar - mas nunca contestar - algo dito e a observar sua realidade para dar exemplos de situações ou circunstâncias que corroboram - mas nunca contradizem - as ideias apresentadas no texto. Não há questões que chamem a atenção para a função do texto e solicitem um posicionamento ativo do aluno com respeito ao modo como os dados e os argumentos são manejados para sustentar as informações e ideias e para dar base às interpretações.

A pós-leitura só é realizada em El arte de leer español, as atividades propostas propiciam a interdisciplinaridade, remetem à realidade do aluno, incentivam a pesquisa, contudo, na maior parte dos casos, não é necessário refletir sobre o texto, mas sim sobre o tema que perpassa a unidade.

Diante do exposto, podemos lançar mão das observações de Marcuschi sobre o trabalho com a compreensão textual realizado por livros didáticos de Língua Portuguesa. O autor identifica quatro problemas com relação à natureza desse trabalho, dos quais é pertinente mencionar os dois últimos:

(3) É comum os exercícios de compreensão nada terem a ver com o texto ao qual se referem, mas serem apenas indagações genéricas ou apenas indagações de ordem subjetiva que podem ser respondidas com qualquer dado.

(4) Os exercícios de compreensão raramente levam a reflexões críticas sobre o texto e não permitem expansão ou construção de sentido, o que reforça a noção de que compreender é apenas identificar conteúdos. (2008, p. 267)

As três coleções não deixam transparecer nas atividades de leitura o quadro de referências presente no edital, sobretudo no que diz respeito à linguagem como atividade social, conforme determinações espaço-temporais de cada cena de interlocução, e como atividade política que envolve valores, concepções e ideologias. Observa-se o apagamento do texto, pois não importa quem o 
escreveu, onde, quando, para quem e por que; importa o que é dito (sobre o tema), mas não como é dito e por quê. Não há em nenhum dos livros, nas seções examinadas, nem uma pergunta sequer que incentive um olhar crítico sobre o texto, questionando-o, buscando seus propósitos, sua função e as representações do mundo contidas nele. Se o texto é apagado, se não é problematizado, está implícito que o que ele diz é verdade e, portanto, a leitura termina sendo ingênua. Por outro lado, também não se procura engajar o aluno como leitor que constrói sentidos a partir de sua realidade e de sua visão de mundo; ele é visto como consumidor das informações que o texto veicula.

\section{E O LETRAMENTO CRÍTICO?}

Trago à discussão o letramento crítico porque se trata de uma proposta de ensino de línguas estrangeiras assumida nas OCEM. Evidentemente, não se pode cobrar das coleções analisadas um trabalho com o texto fundamentado nessa proposta porque ela não foi explicitamente mencionada no edital do PNLD 2012, muito embora, na minha interpretação, possamos encontrá-la sugerida nas entrelinhas do quadro de referências. Minha intenção é falar de uma concepção de leitura que, sem invalidar os modelos linguístico e psicolinguístico, procura levar a compreensão do texto além do uso das estratégias cognitivas e da identificação da intenção do autor. Assim, como explicitam as OCEM,

\footnotetext{
as questões que buscam desenvolver o letramento crítico levam em conta o trabalho que vinha sendo realizado em leitura nas escolas nos últimos anos. Ou seja, continua-se trabalhando a compreensão geral, dos pontos principais e as informações detalhadas do texto, assim como os elementos lingüísticotextuais oferecidos pelos textos selecionados, os quais contribuem para a compreensão e o exercício de interpretação (construção de sentidos). O letramento crítico representa uma ampliação e uma definição desse trabalho de leitura no que se refere à expectativa de desenvolvimento crítico dos alunos. (BRASIL, 2006, p. 116)
}

Na perspectiva do letramento crítico, o conhecimento não é natural nem neutro, baseia-se nas regras discursivas de cada comunidade; as decisões acerca da verdade são construídas num contexto localizado; os significados dos textos são sempre múltiplos, construídos cultural e historicamente, segundo relações de poder. No âmbito educacional, o letramento crítico objetiva o desenvolvimento da consciência crítica. Espera-se que "with critical consciousness as a prominent goal of literacy learning, students not only read texts critically, but they also become actors to transform society" (ibidem, s.p.).

Esses aspectos podem ser desdobrados em pressupostos norteadores para o trabalho com o texto, configurando uma concepção sociocultural de leitura (CASSANY, 2006, p. 33-34; 83):

- tanto o significado das palavras como o conhecimento prévio ativado pelo leitor têm origem social; 
- por trás do texto há um enunciador (individual ou coletivo) e o texto reflete os pontos de vista, a visão de mundo desse enunciador;

- os textos são produzidos e lidos em comunidades e instituições (ou esferas de atividades) específicas;

- cada texto tem uma função na instituição correspondente;

- o texto constrói as representações estabelecidas sobre a realidade (concepções, imaginários, opiniões);

- cada comunidade e cada instituição usam os textos de modo particular, segundo sua identidade e sua história;

- o leitor também tem propósitos sociais concretos.

Tomando como base esses pressupostos, percebe-se que tanto os contextos de produção e circulação do texto como o de sua leitura interferem na compreensão, que passa a ser entendida como construção de sentidos e não como identificação ou inferência de um sentido dado. Desse modo, não se pode desconsiderar quem escreveu o texto, onde e quando, quais eram os seus destinatários (interlocutores) e como ele chegou a esses destinatários. Por isso, é importante que os livros didáticos informem o quem, quando, onde e para quem dos textos, embora esses dados possam ser mais relevantes para a leitura de alguns gêneros textuais (notícias, reportagens, propagandas etc.) do que para outros (receitas culinárias, avisos classificados, formulários etc.).

Outro fator preponderante diz respeito às perguntas propostas para a compreensão leitora: elas devem levar em conta que os alunos não são os leitores originalmente previstos para os textos autênticos usados no livro didático. Sendo assim, ao indicar a discussão sobre a função de um folheto de divulgação de uma campanha comunitária, por exemplo, é necessário considerar o contexto (a comunidade, a instituição) para o qual ele estava dirigido; outra questão é a função desse folheto na sala de aula e as implicações desse novo contexto para a construção de sentidos. Um bom exercício de reflexão crítica, sobretudo considerando a leitura em LE, é discutir, por exemplo, os propósitos de um texto - suponhamos uma notícia intitulada "En cinco años se instalaron 90 nuevas villas en el $G B A^{\prime \prime 6}$, publicada no jornal La Nación (Argentina) - para os seus interlocutores originais e o posicionamento dos alunos diante desse mesmo texto, como leitores situados em outros contextos (a sala de aula de uma escola de periferia de uma região metropolitana, ou da zona rural, ou do centro de uma grande cidade). Segundo Cassany,

el lector crítico asume que los autores y los lectores están situados, que el texto "viaja" de un contexto a otro y, en consecuencia, que puede generar varias interpretaciones. Por ello, no queda satisfecho

\footnotetext{
${ }^{6}$ GBA - Gran Buenos Aires; notícia publica em 05/10/2011, disponível em: http://www.lanacion.com.ar/1411987-en-cinco-anos-se-instalaron-90-nuevas-villas-en-el-gba
} 
con su interpretación personal y dialoga con otros lectores para conocer sus interpretaciones, sumarlas a la suya (incluso si son opuestas) y elaborar lo que podríamos denominar una comprensión social o una idea global del efecto que puede causar un texto. (s. d., p. 29)

Dessa forma, pensando na possibilidade de somar interpretações, a leitura na sala de aula torna-se uma excelente oportunidade para conhecer e contrastar diferentes pontos de vista, expandindo assim as possibilidades de construção de sentidos.

Para promover a compreensão leitora fundamentada no letramento crítico é preciso, contudo, aprofundar o (re)conhecimento das circunstâncias relacionadas aos contextos de partida e de chegada do texto e o confronto de diferentes interpretações. E aqui cabe destacar que não deve haver uma ordem rígida para as atividades com o texto no âmbito escolar, pois cada gênero textual tem suas especificidades e, dependendo do projeto de trabalho pensado em torno dele, pode ser abordado de diversas maneiras. Sendo assim, nem sempre é necessário propor questões de pré e pós-leitura, assim como nem sempre é importante dar ênfase às estratégias de leitura. O que importa é aonde se quer chegar: o desenvolvimento crítico dos alunos.

Comento a seguir alguns procedimentos utilizados em atividades de leitura, acrescidos de sugestões baseadas na concepção sociocultural:

- ativação de conhecimentos prévios e formulação de hipóteses: todas as informações que o texto nos oferece à primeira vista, antes da leitura, são relevantes, criam expectativas e nos predispõem para a formulação de hipóteses não só sobre gênero e o tema tratado, mas também sobre a função, a instituição a que está vinculado e seus prováveis destinatários. Esses conhecimentos são de natureza linguística, discursiva e sociocultural, variam de pessoa para pessoa, devido a diversos fatores dentre eles as práticas de letramento vivenciadas fora da escola - e, apesar de emergirem naturalmente no primeiro contato com o texto, podem e devem ser ativados por meio de perguntas instigantes. É fundamental, todavia, que tais perguntas estimulem a ativação de outros conhecimentos que não venham à mente rapidamente e levem o aluno a refletir sobre a origem dos conhecimentos que possui, principalmente os socioculturais, pois são esses os que costumam condicionar mais fortemente a produção de inferências e a construção de sentidos. Além disso, os alunos podem ser estimulados a avaliar a pertinência dos seus conhecimentos prévios para a compreensão do texto a ser lido, não no intuito de verificar se são certos ou errados, mas sim no de examinar se são ou não limitadores. Uma atitude simples seria perguntar por que nossos conhecimentos nos levam a pensar de determinada forma, a ter determinados valores e levantar determinadas hipóteses. As conjecturas a respeito do conteúdo de um texto muitas vezes revelam ideias e opiniões já cristalizadas e tidas como naturais, normais, comuns. Por essa razão, torna-se 
necessário cotejar hipóteses, discuti-las, questioná-las e averiguar segundo quais critérios são consideradas naturais e se resultam ou não de pré-conceitos que impedem outras formas de pensar. Tomando o exemplo dado anteriormente da notícia publicada no jornal La Nación, intitulada "En cinco años se instalaron 90 nuevas villas en el GBA", podemos nos questionar, por exemplo, que conhecimentos temos sobre as villas (favelas), em Buenos Aires e na região onde moramos, como adquirimos esses conhecimentos e quais referentes construímos mentalmente, de que modo esses referentes influenciam nossas opiniões acerca das favelas e de quem mora ali e nos conduzem a certas expectativas sobre o conteúdo do texto, etc.

- dedução do significado de palavras (des)conhecidas: geralmente as pistas fornecidas pelo próprio texto nos permitem desvendar o que as palavras querem dizer, mesmo aquelas com as quais não estamos familiarizados. Por outro lado, quando as palavras são nossas conhecidas porque podemos associar a elas um determinado referente ou uma função, não costumamos pensar se elas adquirem outros matizes no texto e lhe atribuímos a acepção mais frequente. Portanto, é importante refletir sobre o que as palavras mostram, ocultam (duplos sentidos, ironias, ambiguidades, conotações) ou reforçam e, mais ainda, sobre como podem induzir a produção de inferências. Se compararmos o título da notícia usada aqui como exemplo - "En cinco años se instalaron 90 nuevas villas en el $G B A$ " -, com “En cinco años se instalaron 90 villas en el GBA", que mudança de sentido(s) perceberemos? Certamente, podemos dizer que o adjetivo nuevas nos leva a inferir que, antes dessas, já existiam villas na grande Buenos Aires. Esse exemplo simples ilustra que os significados das palavras ultrapassam as definições dos dicionários e muitas vezes transportam informações - e também ideias, opiniões, valores, julgamentos - que não estão formuladas explicitamente no texto. Sendo assim, buscar o que as palavras escondem e verificar como elas nos possibilitam construir diferentes sentidos é adotar uma postura crítica perante o texto;

- reconhecimento de informações implícitas e produção de inferências: pode-se dizer que graças a nossa capacidade de recuperar o que está implícito e de inferir podemos dar e ouvir menos explicações, definições e justificativas na nossa vida diária. Do mesmo modo, ao produzir um texto, informações podem ser omitidas e pontos de vista podem ser apenas sugeridos porque se pressupõe que o leitor terá condições de ler nas entrelinhas e encontrar o que está oculto, como vimos no parágrafo anterior. Essas operações cognitivas podem ser simples ou complexas, dependendo da familiaridade do leitor com o gênero textual e dos conhecimentos prévios que possui não só sobre $\mathrm{o}(\mathrm{s}) \operatorname{assunto}(\mathrm{s})^{7}$ tratado(s), mas também sobre as circunstâncias de produção e circulação do texto. No âmbito do ensino-aprendizagem de LE, é fundamental propiciar aos alunos as condições para que

${ }^{7}$ Uso a palavra assuntos como uma forma de generalização, pois podem ser referências a pessoas, fatos, lugares, situações, datas etc. 
possam usar essas estratégias em benefício de seu desenvolvimento crítico, mas, para que isso aconteça primeiramente é preciso: prever as informações que os estudantes não possuem e pensar em meios pelos quais possam obtê-las (pesquisa, texto complementar, consultas etc.); propor questões que chamem a atenção para os implícitos que podem ser recuperados com os conhecimentos já adquiridos; e fazer indagações que os ajudem a ler as entrelinhas. Não se trata, obviamente, de estabelecer um roteiro para chegar a uma interpretação pré-estabelecida, mas sim de motivar o aluno a ir além do que está na superfície do texto.

Segundo Cassany (2006), a compreensão crítica pressupõe poder fazer muitas inferências, mas o autor chama a atenção para o fato de que compreender requer reconstruir tanto o conteúdo como a ideologia do texto e poder dar-lhes sentido no mundo pessoal. Para esclarecer o que se deve entender por ideologia, em outro texto ele diz:

\footnotetext{
Desde una perspectiva sociocultural, se asume como axioma que los textos tienen siempre un "autor" de carne y hueso, que vive en un lugar y momento y que pertenece a una cultura, y que su punto de vista se proyecta siempre en sus textos (ese autor puede ser explícito o anónimo, individual o colectivo, etc.). La ideología consiste entonces en esta perspectiva que adopta el texto sobre cualquier tema (ecología, feminismo, desarrollo, economía, política, deporte, vegetarianismo, catolicismo, etc.), y no se considera algo negativo. Es algo que está siempre en todos los textos, con mayor o menor presencia, y que constituye una parte importante de la comprensión. (s.d., p. 24)
}

Portanto, usar as inferências em benefício do desenvolvimento da consciência crítica significa identificar as representações do mundo explícitas e implícitas no texto e questionar: por que são assim e não de outro jeito? Retomando o exemplo dado anteriormente, podemos indagar que representação da realidade começa a ser configurada a partir do título "En cinco años se instalaron 90 nuevas villas en el GBA". Lendo a notícia, certamente encontraremos outros elementos gramaticais, discursivos, gráficos - que reiterarão essa representação ou a desconstruirão para construir outra. É por meio desses elementos que se projeta o ponto de vista do autor - a perspectiva adotada, a ideologia. Por outra parte, o ponto de vista do leitor - a sua ideologia - também se projeta nos textos que lê, pois, assim como o autor, ele é um sujeito de carne e osso, que vive num lugar, em dado momento, e pertence a uma cultura. Discutir e confrontar os diversos pontos de vista, buscando entender como e por que se constroem de determinada maneira, em detrimento de outras possibilidades, são tarefas que devem fazer parte do trabalho de compreensão leitora na sala de aula de língua estrangeira.

\section{CONCLUSÕES PROVISÓRIAS}


Constatamos na análise das atividades de compreensão leitora das três coleções de espanhol aprovadas no PNLD 2012 o predomínio das concepções linguística e psicolinguística de leitura, mas essa constatação não implica que o trabalho proposto seja desnecessário ou inválido, pelo contrário, centrar a atenção no código e no uso de estratégias cognitivas é uma etapa importante no trabalho com o texto, principalmente no âmbito de ensino-aprendizagem de línguas estrangeiras. Além disso, não podemos desconsiderar os diversos fatores que dificultam a proposta de atividades voltadas para a interação com o texto/autor e para o desenvolvimento da consciência crítica. Por ser um processo minucioso e longo, que precisa incluir questões de respostas abertas ${ }^{8}$ e contar com diferentes possibilidades de interpretação, o livro didático acaba sendo um espaço quase impróprio para um trabalho diferenciado de leitura, pois deve atender também a requisitos relacionados às outras habilidades e aos conteúdos linguísticos. Devemos levar em conta igualmente fatores relativos ao contexto escolar: carga horária reservada às LE (às vezes, apenas 1hora/aula por semana), turmas numerosas, necessidade de contemplar a produção escrita, a expressão e a compreensão oral etc.

Diante desse panorama, parece inviável a leitura na sala de aula a partir de outras perspectivas, assim como parece difícil que o livro didático, tendo de considerar requisitos tais como os do PNLD 2012, possa fazer mais do que já faz em termos de compreensão leitora. Certamente há alternativas, mas elas fogem aos propósitos deste artigo e dependem de outras condições, já que qualquer mudança no âmbito da língua estrangeira está atrelada a mudanças na educação como um todo.

Por ora, podemos nos contentar com a opção de complementar o livro didático, ampliando as atividades oferecidas por ele, mas sem perder de vista que o trabalho de compreensão leitora não pode reduzir o texto a um único ponto de vista, seja do autor, do professor, do autor do livro didático ou de um aluno em particular. Não há interpretações definitivas, embora haja interpretações plausíveis, ou seja, não se pode atribuir qualquer sentido ao texto. Os sentidos se constroem e se complementam num caminho que vai do individual ao coletivo e vice-versa. Por isso, a sala de aula pode ser um lugar privilegiado para a leitura na perspectiva do letramento crítico.

\section{REFERÊNCIAS BIBLIOGRÁFICAS}

BRASIL - MEC-FNDE. Edital de convocação para inscrição no processo de avaliação e seleção de coleções didáticas para o programa nacional do livro didático - PNLD 2012. Brasília: Ministério de Educação, FNDE, 2009. Disponível em:

\footnotetext{
${ }^{8}$ Não digo respostas livres porque faço restrições a essa qualificação. Dizer que são livres parece significar que se pode responder qualquer coisa.
} 
http://www.fnde.gov.br/index.php/edital-pnld-2012-ensino-medio Acesso em: 25 de ago. 2011

BRASIL - MEC-SEB. Orientações curriculares para o ensino médio. Linguagens, códigos e suas tecnologias. Brasília: Ministério da Educação, Secretaria de Educação Básica, 2006, volume 1.

BRASIL - MEC/SEF. Parâmetros curriculares nacionais: terceiro e quarto ciclos do ensino fundamental: língua estrangeira. Brasília: MEC, Secretaria de Ensino Fundamental, 1998.

CASSANY, D. Prácticas letradas contemporáneas: claves para su desarrollo. (s.d.)

Disponível em:

http://www.leer.es/wp-

content/uploads/webcast/documentos/practicas_letradas/presentacion_DanielCassany.pdf Acesso em: 15 de abr. 2011

CASSANY, D. Tras las líneas. Sobre la lectura contemporánea. Barcelona: Anagrama, 2006.

CERVETTI, G.; PARDALES, M. J.; DAMICO, J. S. A tale of differences: comparing the traditions, perspectives, and educational goals of critical reading and critical literacy.

http://www.readingonline.org/articles/art_index.asp?HREF=/articles/cervetti/index.html Acesso em: 30 de ago. 2011

KATO, M. O aprendizado da leitura. São Paulo: Martins Fontes, 1985.

MARCUSCHI, L. A. Produção textual, análise de gêneros e compreensão. São Paulo: Parábola Editorial, 2008.

MARTIN, I. Síntesis. São Paulo: Ática, 2010.

OSMAN, S. et al. Enlaces. São Paulo: Macmillan, 2010.

PICANÇO, D. C. L.; VILLALBA, T. K. B. El arte de leer español. Curitiba Base Editorial, 2010. 